\title{
Fluorescence Lifetime Imaging of Propranolol Uptake in Living Glial C6 Cells
}

\author{
Roger Bisby, ${ }^{1}$ Stanley Botchway, ${ }^{2}$ Ana Crisostomo, ${ }^{1}$ Anthony Parker, ${ }^{2}$ and Kathrin Scherer ${ }^{1}$ \\ ${ }^{1}$ Biomedical Research Centre, University of Salford, Salford M5 4WT, UK \\ ${ }^{2}$ Rutherford Appleton Laboratory, Central Laser Facility, Research Complex at Harwell, Science and \\ Technologies Facility Council, Chilton, Harwell Oxford, Oxon OX11 OQX, UK
}

Correspondence should be addressed to Roger Bisby, r.h.bisby@salford.ac.uk

Copyright (C) 2012 Roger Bisby et al. This is an open access article distributed under the Creative Commons Attribution License, which permits unrestricted use, distribution, and reproduction in any medium, provided the original work is properly cited.

\begin{abstract}
Uptake of the $\beta$-blocker drug propranolol by living glial C6 cells has been observed using fluorescence lifetime imaging with two-photon excitation at $630 \mathrm{~nm}$. Both uptake and release of propranolol occur within minutes and are temperature dependent, being about 5 times faster at $37^{\circ} \mathrm{C}$ than at $20^{\circ} \mathrm{C}$. The intracellular fluorescence lifetime of propranolol is generally shorter than the value of $9.8 \mathrm{~ns}$ determined in dilute neutral aqueous solution, and the difference is ascribed to concentration quenching. Within the cells, propranolol is accumulated within intracellular acidic vesicles and the cytoplasm but is excluded from the cell nucleus. On incubation of cells in medium containing $100 \mu \mathrm{M}$ propranolol, the drug is accumulated to reach intracellular concentrations up to $10 \mathrm{mM}$ in a process that is believed to be driven by protonation within acidic cellular compartments.
\end{abstract}

Keywords: Propranolol, fluorescence, lifetime, imaging, multiphoton, living cell

\section{Introduction}

Propranolol is a nonselective $\beta$-blocker drug which prevents binding of epinephrine and noradrenaline to $\beta 1$ - and $\beta 2$-andrenergic receptors [1] as well as inhibiting cellular uptake of both serotonin and dopamine [2]. Propranolol is a weakly basic lipophilic compound known to interact and modify the behaviour of bilayer lipid membranes [3-5]. Studies have shown propranolol to be taken up into a range of cells including epithelial cells [6] and hepatocytes [7]. In the latter case, it has recently been reported that there are two intracellular sites, one of high affinity and low capacity, and the other a low affinity and nonsaturable site proposed to be the cellular membranes [7].

It is known that propranolol exhibits intrinsic fluorescence in the ultraviolet region with a solventdependent maximum between 320 and $360 \mathrm{~nm}$ [8-11]. This has been used for a number of purposes, including quantification of propranolol in drug assays, detection during microchip electrophoresis, and monitoring binding to imprinted polymers. However, the wavelengths required for one-photon fluorescence excitation in the ultraviolet $(260-320 \mathrm{~nm})$ are damaging to cellular systems, producing potentially toxic intermediates [12], and are poorly transmitted by normal microscope optics [13]. These constraints therefore make difficult direct excitation and imaging of propranolol fluorescence 
in cellular systems with UV excitation. In contrast, two-photon microscopy using red and near infrared wavelengths with the benefit of confining the region of excitation to the focal volume of a femtosecond laser beam focussed to the diffraction limit, which further allows pseudoconfocal imaging $[14,15]$ with reduced overall phototoxicity. Multiphoton microscopy has applications in pharmaceutical sciences [16] effectively permitting imaging of UV intrinsic fluorescence from biochemical chromophores such as serotonin $[17,18]$ and dehydroergosterol [19].

\section{Materials and Methods}

Reagents

All chemicals were obtained from Sigma-Aldrich and used as received. The rat glioma line, designated as C6 glial cells, was purchased from LGC Promochem (ATCC number CCL-107). They were grown as monolayer cultures in F-12 K medium supplemented with $2.5 \%(\mathrm{v} / \mathrm{v}) \mathrm{FCS}$ at $37^{\circ} \mathrm{C}$ with humidified $5 \% \mathrm{CO}_{2}$. For imaging, cells were treated with $0.25 \%$ trypsin and seeded into dishes with a number 1 coverslip base (MaTek Corporation) at a concentration of $\sim 2.5 \times 10^{5}$ cells $\mathrm{mL}^{-1}$ and grown for over 50 hours.

The microscope system for fluorescence lifetime imaging has been previously described [18]. Briefly, it is based on a Ti: sapphire laser (Coherent Mira) pumping an optical parametric oscillator (APE) coupled to an inverted microscope (Nikon TE2000U) with a water-immersion ultraviolet corrected objective (Nikon VC x60, NA 1.2). For cell work, power at the sample was limited to $<1 \mathrm{~mW}$ to minimize localised photodamage. Fluorescence was detected through a combination of a saturated copper sulphate solution and $340 \mathrm{~nm}$ (U340, Comar) interference filters using time-correlated single photon counting with a Hamamatsu R3809U photomultiplier linked to a PC module SPC830 (Becker and Hickl, Germany).

\section{Results and Discussion}

In aqueous solution at $\mathrm{pH} 7.3$, propranolol and tryptophan have similar absorption maxima at about 280-290 nm with comparable extinction coefficients (see Table 1). However, excitation on the red edge at 310-320 nm allows selective stimulation of propranolol fluorescence in the presence of tryptophancontaining proteins in a manner analogous to that previously described for observation of serotonin and 5-hydroxytryptophan fluorescence [18, 23]. For propranolol, the long wavelength absorption peak is at $289 \mathrm{~nm}\left(\varepsilon=5,900 \mathrm{M}^{-1} \mathrm{~cm}^{-1}\right)$ whilst the extinction coefficient at $315 \mathrm{~nm}$ is $1,730 \mathrm{dm}^{3} \mathrm{~mol}^{-1} \mathrm{~cm}^{-1}$. In neutral aqueous solution, the fluorescence spectrum of propranolol has a peak at $353 \mathrm{~nm}$ and overlaps substantially with that of tryptophan. The fluorescence quantum yield $\left(\phi_{f}\right)$ of $0.50 \pm 0.03$ for propranolol at $\mathrm{pH} 7.3$ was measured on excitation of $315 \mathrm{~nm}$ by comparison of the integrated fluorescence intensities in solutions of matched absorbance values when using 5-hydroxytryptophan as a standard $\left(\phi_{f}=0.27[21]\right)$.

For imaging studies of cells, 2-photon excitation (2PE) at around $630 \mathrm{~nm}$ was achieved using laser pulses of $180 \mathrm{fs}$ duration at a repetition frequency of $76 \mathrm{MHz}$. Under these conditions, propranolol fluorescence intensity exhibits the anticipated quadratic dependence on laser power. two-photon crosssections $\left(\sigma_{2}\right)$ for propranolol as the sample $(s)$ at $590 \mathrm{~nm}$ and $630 \mathrm{~nm}$ were obtained by the method 
Table 1: Spectroscopic properties of tryptophan, serotonin, and propranolol including fluorescence quantum yields $\left(\phi_{f}\right)$, fluorescence lifetimes $\left(\tau_{f}\right)$, and 2-photon excitation cross sections $\left(\sigma_{2}\right)$.

\begin{tabular}{lccc}
\hline & Propranolol & Serotonin & Tryptophan \\
\hline$\varepsilon(295 \mathrm{~nm})^{\mathrm{a}}$ & 5310 & 4280 & 1490 \\
$\varepsilon(315 \mathrm{~nm})^{\mathrm{a}}$ & 1730 & 1140 & 20 \\
$\phi_{f}$ & $0.50 \pm 0.03$ & $0.28[20]$ & $0.27[21]$ \\
$\tau_{f}(\mathrm{~ns})$ & 9.8 & $3.9[20]$ & $2.79,0.26[21]$ \\
$\sigma_{2}(590 \mathrm{~nm})^{\mathrm{b}}$ & 0.40 & 0.94 & $0.21[22]$ \\
$\sigma_{2}(630 \mathrm{~nm})^{\mathrm{b}}$ & $0.17^{\mathrm{c}}, 0.22^{\mathrm{d}}$ & 0.35 & - \\
\hline
\end{tabular}

${ }^{a}$ Units $\mathrm{M}^{-1} \mathrm{~cm}^{-1}$, ${ }^{\mathrm{b}} \mathrm{GM}$ units $\left(10^{-50} \mathrm{~cm}^{4} \mathrm{sphoton}^{-1}\right)$, ${ }^{\mathrm{c}}$ determined using tryptophan as standard, ${ }^{\mathrm{d}}$ determined with 9chloroanthracene as standard.

outlined by Mathai et al. (2007) [24] using a reference fluorophore $(r)$ with a known value of $\sigma_{2 r}$ using (3.1), in which $I$ represents the measured fluorescence intensity in the two-photon experiment, $c$ the concentration, $\phi$ the fluorescence quantum yield, and $\mathrm{FI}^{\lambda}$ the fluorescence intensity of the fluorophore in the one-photon excited spectrum at the wavelength $\lambda$ used in the two-photon experiment relative to the integrated spectral intensity $\Sigma$ FI:

$$
\sigma_{2 s}=\frac{I_{s} \cdot c_{r} \cdot\left(\mathrm{FI}_{r}^{\lambda} / \Sigma \mathrm{FI}_{r}\right) \cdot \phi_{r}}{I_{r} \cdot c_{s} \cdot\left(\mathrm{FI}_{s}^{\lambda} / \Sigma \mathrm{FI}_{s}\right) \cdot \phi_{s}} \cdot \sigma_{2 r} .
$$

Using this method for determination of cross-sections at one excitation wavelength (here $590 \mathrm{~nm}$ ) effectively calibrates the sensitivity of the emission/detection section of the apparatus and allows determination of cross-sections at other excitation wavelengths. Only corrections for the transmission of the microscope objective at the excitation wavelength and laser power at each excitation wavelength are required. A two-photon excitation spectrum for tryptophan has been reported by Rehms and Callis [22] and $\sigma_{2}$ of $1.9 \mathrm{GM}$ units $\left(10^{-50} \mathrm{~cm}^{4} \mathrm{~s}_{\text {photon }}{ }^{-1}\right)$ calculated for 3-methyl indole at $552 \mathrm{~nm}$. Their data suggests $\sigma_{2 r}$ of $0.21 \mathrm{GM}$ for tryptophan two-photon excitation at $590 \mathrm{~nm}$, and this was used as one of the standard values. The results summarised in Table 1 indicate values of $\sigma_{2}$ of 0.40 and $0.17 \mathrm{GM}$ units for propranolol at 590 and $630 \mathrm{~nm}$, respectively. The corresponding cross-sections for serotonin are shown for comparison and are approximately twofold higher than for propranolol despite the lower extinction coefficients for the former at 295 and $315 \mathrm{~nm}$. For comparison, a second determination of $\sigma_{2}$ for propranolol was made with $2 \mathrm{PE}$ at $628 \mathrm{~nm}$ using 9-chloroanthracene as a standard with $\sigma_{2 r}=0.20 \mathrm{GM}$ at $630 \mathrm{~nm}$ [25]. Using again the method outlined by Mathai et al. [24], a value of $\sigma_{2}$ for propranolol of $0.22 \mathrm{GM}$ at $628 \mathrm{~nm}$ was obtained which is in excellent agreement with the value of $0.17 \mathrm{GM}$ units obtained with tryptophan as the standard.

Fluorescence lifetimes of propranolol under various conditions were measured using two-photon excitation at $630 \mathrm{~nm}$ with the microscope system and placing a drop of solution on a coverslip mounted on the thermostatically controlled microscope stage. At $20^{\circ} \mathrm{C}$ in dilute neutral aqueous solution, a good single exponential lifetime of $10.1 \mathrm{~ns}\left(\chi^{2}=1.03\right)$ was measured. Buffering the solution with phosphate resulted in a slight decrease in lifetime to $9.8 \mathrm{~ns}$ in $0.1 \mathrm{~mol} \mathrm{dm}^{3}$ phosphate. As shown in Figure 1(a), the lifetime remained constant over the range $\mathrm{pH} 5$ to 8.5 but decreased in alkaline solutions in a manner 


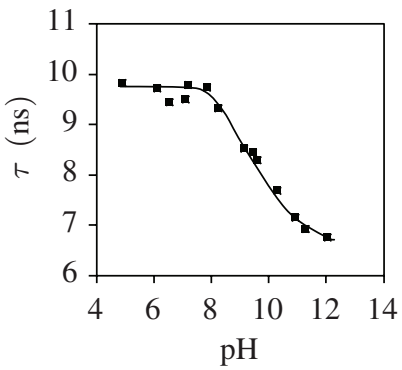

(a)

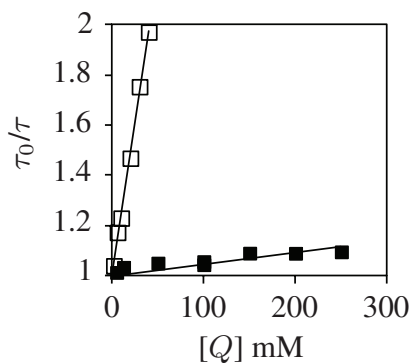

(b)

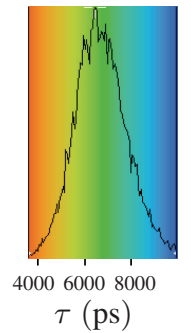

(c)

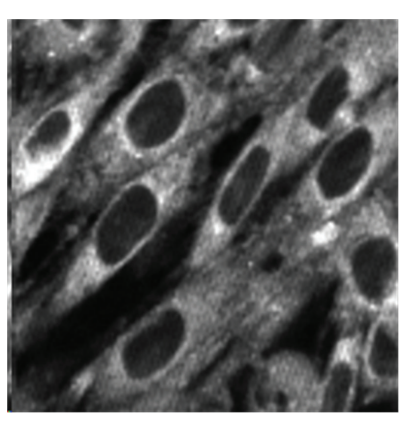

(d)
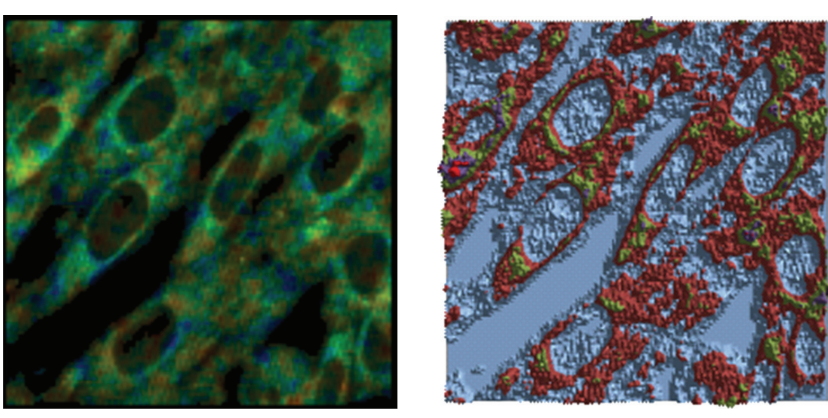

[Propranolol] $\mathrm{mM}$

$$
\begin{array}{ll}
0-2 & =6-8 \\
2-4 & -8-10 \\
4-6 &
\end{array}
$$

(e)

(f)

Figure 1: Fluorescence of propranolol in solution and after uptake into $\mathrm{C} 6$ glial cells. (a) Effect of pH on the fluorescence lifetime of propranolol in aqueous solution; (b) Stern-Volmer plots at $\mathrm{pH} 7$ for the self-quenching of the fluorescence lifetime of propranolol $(\square)$ and quenching by phosphate ( $\square$ ). Images (c) through (f) show results obtained on incubation of C6 glial cells with SR-propranolol $(100 \mu \mathrm{M})$ at $37^{\circ} \mathrm{C}$ for 10 minutes. Fluorescence at $340 \mathrm{~nm}$ was observed following $2 \mathrm{PE}$ at $630 \mathrm{~nm}$. The results show the fluorescence intensity (d) and lifetime (e) images (field $76 \mu \mathrm{m}$ square) together with the lifetime distribution within the image (c). Image (f) shows the intracellular propranolol concentration profile calculated from (d) and (e) as described in the text.

consistent with a the reported $\mathrm{pK}_{\mathrm{a}}$ of 9.53 [26]. At $37^{\circ} \mathrm{C}$ in neutral aqueous solution, the fluorescence lifetime also decreased to $9.4 \mathrm{~ns}$. Self-quenching of the fluorescence lifetime at concentrations above $1 \mathrm{mM}$ was measured and followed Stern-Volmer kinetics for kinetic quenching, plotted according to (3.2) in Figure 1(b) giving a second-order rate constant, $k_{q}$, of $(2.5 \pm 0.1) \times 10^{9} \mathrm{M}^{-1} \mathrm{~s}^{-1}$ :

$$
\frac{\tau_{0}}{\tau}=1+k_{q} \tau_{0}[Q]
$$

which is close to the diffusion-controlled limit. Weaker kinetic quenching of the propranolol fluorescence lifetime by phosphate at $\mathrm{pH} 7$ was also observed with $k_{q}(3.2 \pm 0.5) \times 10^{7} \mathrm{M}^{-1} \mathrm{~s}^{1}$. The lifetimes measured for propranolol in dilute solutions are longer than those of tryptophan (major long 
lifetime component $2.88 \mathrm{~ns}$ [21]) enabling good discrimination against intrinsic tryptophan fluorescence in biochemical systems as demonstrated below.

\section{Intracellular Imaging of Propranolol}

C6 cells are capable of protecting neuronal cells against excessive levels of monoamines through sodium- and chloride-dependent monoamine transporters [27]. Using the fluorescence properties of propranolol described above, it proved possible to image intracellular accumulation of propranolol in cells using two-photon fluorescence lifetime imaging with excitation at $630 \mathrm{~nm}$ and detection of ultraviolet $(340 \mathrm{~nm})$ fluorescence. Uptake was initiated by addition of propranolol $(100 \mu \mathrm{M}$ final concentration) to the culture medium above a confluent monolayer of cells attached to a cover-slip forming part of a thermostatically controlled chamber. A typical image obtained after incubation of C6 cells with propranolol at $37^{\circ} \mathrm{C}$ is shown in Figure 1. The intensity image (Figure 1(d)) shows propranolol mainly distributed within the cell cytoplasm and excluded from the cell nucleus. The fluorescence lifetime image (Figure 1(e)) indicates a range of lifetimes from the solution value of $9.4 \mathrm{~ns}$ at $37^{\circ} \mathrm{C}$ to quenched values of less than $5 \mathrm{~ns}$, with an average value of approximately $6.5 \mathrm{~ns}$ (Figure 1(c)). Calibration of the microscope system with propranolol solutions of known concentration allows an estimate of intracellular propranolol concentrations after correcting for Stern-Volmer quenching using the lifetime data. Plots of fluorescence intensities of the calibration solutions versus concentration themselves required correction because of the effects of self-quenching according to (3.2). Applying a similar lifetime adjustment to the cell intensity data provides a concentration map of propranolol concentration within the cells (Figure 1(f)). It can be seen that substantial regions of the cell cytoplasm contain around $5 \mathrm{mM}$ propranolol with peak concentrations reaching up to $10 \mathrm{mM}$. These values are up to two orders of magnitude higher than the concentration of propranolol $(100 \mu \mathrm{M})$ added to the external medium.

The rates of accumulation of propranolol within C6 glial cells were evaluated by measuring the total fluorescence intensity within the microscope field. Figure 2 (a) shows that at $37^{\circ} \mathrm{C}$ uptake was rapid and occurred with a half-life of less than 2 minutes. Although S-propranolol is about 100 times more effective as a drug than R-propranolol, no significant difference in the rate of uptake between the 2 enantiomers and a racemic mixture was observed. At $22^{\circ} \mathrm{C}$, the rate of uptake was much slower with a half-life of about 15 minutes. The loss of propranolol from previously loaded cells could also be measured on replacement of the external medium containing propranolol with phosphate-buffered saline. The results in Figure 2(b) show half-lives of $<2$ and 8 minutes at 37 and $20^{\circ} \mathrm{C}$ respectively.

Propranolol is a weak base $\left(\mathrm{pK}_{\mathrm{a}}=9.53\right)$ and is known to accumulate within acidic vesicles through protonation and trapping of the acidic form [28]. our previous imaging experiments [29] with rat smooth muscle aorta cells show colocalisation of propranolol with Lysotracker Green DND-26 at $20^{\circ} \mathrm{C}$, but more extensive distribution through the cell cytoplasm at $37^{\circ} \mathrm{C}$. Further imaging experiments in $\mathrm{C} 6$ glial cells (not shown) provide further support for this and suggest that initial accumulation occurs in lysosomes and mitochondria. At higher temperatures, the incorporation of propranolol into the membranes of these organelles, due to the lipophilicity of the drug, may lead to leakage into more widespread regions of the cell cytoplasm. The rate of propranolol uptake observed directly in these fluorescence lifetime imaging experiments is in accordance with previous nonimaging measurements using radiochemical analysis [7]. The fluorescence method here, however, not only gives details of uptake but also enables direct imaging of the intracellular location and concentration of the accumulated drug. 


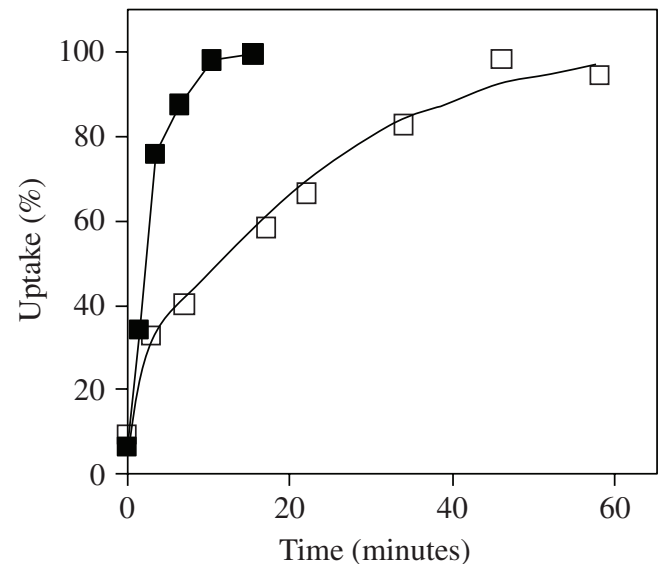

(a)

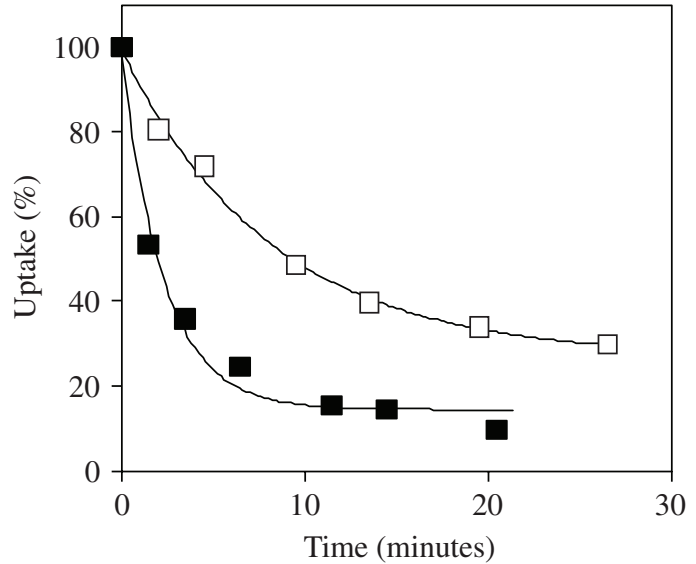

(b)

Figure 2: Time courses for uptake and release of propranolol from rat C6 glial cells. Uptake (a) was measured at $37^{\circ} \mathrm{C}$ from a solution containing SR-propranolol $(100 \mu \mathrm{M}$, $\mathbf{0})$ and at $22^{\circ} \mathrm{C}$ with S-propranolol $(100 \mu \mathrm{M}, \square)$. Cells previously loaded with propranolol $(100 \mu \mathrm{M})$ were washed with phosphate-buffered saline to observe release (b) of SR-propranolol at $37^{\circ} \mathrm{C}(\boldsymbol{\square})$ and $22^{\circ} \mathrm{C}(\square)$.

\section{Acknowledgments}

We thank STFC BioMedical Network and the University of Salford for providing studentships to Ana Crisostomo and Kathrin Scherer and STFC for providing access to the Lasers for Science Facility at Rutherford Appleton Laboratory. Thanks are also due to Mrs. P. Reynolds and Dr. Rahul Yadav for assistance with cell culture.

\section{References}

[1] J. W. Black, W. A. Duncan, and R. G. Shanks, "Comparison of some properties of pronethalol and propranolol,” British Journal of Pharmacology, vol. 25, no. 3, pp. 577-591, 1965.

[2] E. Keating, C. Lemos, R. Monteiro, I. Azevedo, and F. Martel, "The effect of a series of organic cations upon the plasmalemmal serotonin transporter, SERT," Life Sciences, vol. 76, no. 1, pp. 103-119, 2004.

[3] W. K. Surewicz and W. Leyko, "Interaction of propranolol with model phospholipid membranes Monolayer, spin label and fluorescence spectroscopy studies," Biochimica et Biophysica Acta, vol. 643, no. 2, pp. 387-397, 1981.

[4] S. Butler, R. Wang, S. L. Wunder, H. Y. Cheng, and C. S. Randall, "Perturbing effects of carvedilol on a model membrane system: role of lipophilicity and chemical structure," Biophysical Chemistry, vol. 119, no. 3, pp. 307-315, 2006.

[5] E. Varga, J. Szöllosi, K. Antal, P. Kovács, and J. Z. Szabó, "Nonspecific membrane effects of CH103: hydrophobicity, surface activity and membrane fluidity studies in comparison with propranolol and practolol," Pharmazie, vol. 54, no. 5, pp. 380-384, 1999.

[6] G. Cramb, "Selective lysosomal uptake and accumulation of the beta-adrenergic antagonist propranolol in cultured and isolated cell systems," Biochemical Pharmacology, vol. 35, no. 8, pp. 1365-1372, 1986. 
[7] D. Hallifax and J. B. Houston, "Uptake and intracellular binding of lipophilic amine drugs by isolated rat hepatocytes and implications for prediction of in vivo metabolic clearance," Drug Metabolism and Disposition, vol. 34, no. 11, pp. 1829-1836, 2006.

[8] C. E. Hunt and R. J. Ansell, "Use of fluorescence shift and fluorescence anisotropy to evaluate the re-binding of template to (S)-propranolol imprinted polymers," Analyst, vol. 131, no. 5, pp. 678-683, 2006.

[9] P. Schulze, M. Ludwig, F. Kohler, and D. Belder, "Deep UV laser-induced fluorescence detection of unlabeled drugs and proteins in microchip electrophoresis," Analytical Chemistry, vol. 77, no. 5, pp. 1325-1329, 2005.

[10] F. Zhang, Y. Du, B. Ye, and P. Li, "Study on the Interaction between the chiral drug of propranolol and $\alpha 1$-acid glycoprotein by fluorescence spectrophotometry," Journal of Photochemistry and Photobiology B, vol. 86, no. 3, pp. 246-251, 2007.

[11] R. H. Bisby, S. W. Botchway, A. G. Crisostomo, J. Karolin, A. W. Parker, and L. Schröder, "Interactions of the $\beta$-blocker drug, propranolol, with detergents, $\beta$-cyclodextrin and living cells studied using fluorescence spectroscopy and imaging," Spectroscopy, vol. 24, no. 1-2, pp. 137-142, 2010.

[12] R. H. Bisby, A. G. Crisostomo, S. W. Botchway, and A. W. Parker, "Nanoscale hydroxyl radical generation from multiphoton ionization of tryptophan," Photochemistry and Photobiology, vol. 85, no. 1 , pp. 353-357, 2009.

[13] K. Konig, "Multiphoton microscopy in life sciences," Journal of Microscopy, vol. 200, no. 2, pp. 83-104, 2000.

[14] C. Xu, W. Zipfel, J. B. Shear, R. M. Williams, and W. W. Webb, "Multiphoton fluorescence excitation: new spectral windows for biological nonlinear microscopy," Proceedings of the National Academy of Sciences of the United States of America, vol. 93, no. 20, pp. 10763-10768, 1996.

[15] A. Ustione and D. W. Piston, "A simple introduction to multiphoton microscopy," Journal of Microscopy, vol. 243, no. 3, pp. 221-226, 2011.

[16] C. J. Strachan, M. Windbergs, and H. L. Offerhaus, "Pharmaceutical applications of non-linear imaging," International Journal of Pharmaceutics, vol. 417, pp. 163-172, 2011.

[17] R. M. Williams, J. B. Shear, W. R. Zipfel, S. Maiti, and W. W. Webb, "Mucosal mast cell secretion processes imaged using three-photon microscopy of 5-hydroxytryptamine autofluorescence," Biophysical Journal, vol. 76, no. 4, pp. 1835-1846, 1999.

[18] S. W. Botchway, A. W. Parker, R. H. Bisby, and A. G. Crisostomo, "Real-time cellular uptake of serotonin using fluorescence lifetime imaging with two-photon excitation," Microscopy Research and Technique, vol. 71, no. 4, pp. 267-273, 2008.

[19] D. Wüstner, J. R. Brewer, L. Bagatolli, and D. Sage, "Potential of ultraviolet wide-field imaging and multiphoton microscopy for analysis of dehydroergosterol in cellular membranes," Microscopy Research and Technique, vol. 74, no. 1, pp. 92-108, 2011.

[20] A. Chattopadhyay, R. Rukmini, and S. Mukherjee, "Photophysics of a neurotransmitter: ionization and spectroscopic properties of serotonin," Biophysical Journal, vol. 71, no. 4, pp. 1952-1960, 1996.

[21] K. Lotte, R. Plessow, and A. Brockhinke, "Static and time-resolved fluorescence investigations of tryptophan analogues-a solvent study," Photochemical and Photobiological Sciences, vol. 3, no. 4, pp. 348-359, 2004.

[22] A. A. Rehms and P. R. Callis, "Two-photon fluorescence excitation spectra of aromatic amino acids," Chemical Physics Letters, vol. 208, no. 3-4, pp. 276-282, 1993.

[23] C. W. V. Hogue, I. Rasquinha, A. G. Szabo, and J. P. MacManus, "A new intrinsic fluorescent probe for proteins. Biosynthetic incorporation of 5-hydroxytryptophan into oncomodulin," FEBS Letters, vol. 310, no. 3, pp. 269-272, 1992. 
[24] S. Mathai, D. K. Bird, S. S. Stylli, T. A. Smith, and K. P. Ghiggino, "Two-photon absorption crosssections and time-resolved fluorescence imaging using porphyrin photosensitisers," Photochemical and Photobiological Sciences, vol. 6, no. 9, pp. 1019-1026, 2007.

[25] N. S. Makarov, M. Drobizhev, and A. Rebane, "Two-photon absorption standards in the 550$1600 \mathrm{~nm}$ excitation wavelength range," Optics Express, vol. 16, no. 6, pp. 4029-4047, 2008.

[26] A. L. Upthagrove and W. L. Nelson, "Importance of amine pKa and distribution coefficient in the metabolism of fluorinated propranolol derivatives. Preparation, identification of metabolite regioisomers, and metabolism by CYP2D6," Drug Metabolism and Disposition, vol. 29, no. 11, pp. 1377-1388, 2001.

[27] J. Liu and J. M. Lauder, "Serotonin promotes region-specific glial influences on cultured serotonin and dopamine neurons," Glia, vol. 5, no. 4, pp. 306-317, 1992.

[28] P. R. Cullis, M. J. Hope, M. B. Bally, T. D. Madden, L. D. Mayer, and D. B. Fenske, "Influence of $\mathrm{pH}$ gradients on the transbilayer transport of drugs, lipids, peptides and metal ions into large unilamellar vesicles," Biochimica et Biophysica Acta, vol. 1331, no. 2, pp. 187-211, 1997.

[29] R. H. Bisby, A. G. Crisostomo, S. W. Botchway, A. W. Parker, and S. W. Watts, "Intracellular imaging of serotonin and propranolol in rat aorta cells," Central Laser Facility Annual Report 2008/2009 RAL-TR-2009-025, 2009. 


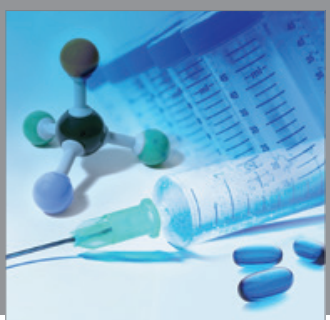

International Journal of

Medicinal Chemistry

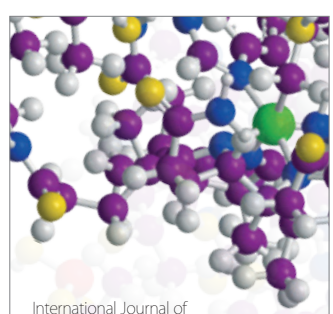

Carbohydrate Chemistry

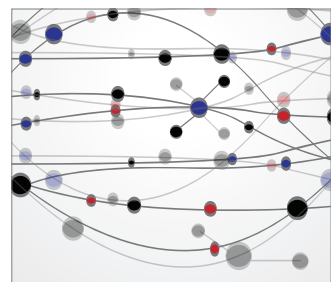

The Scientific World Journal
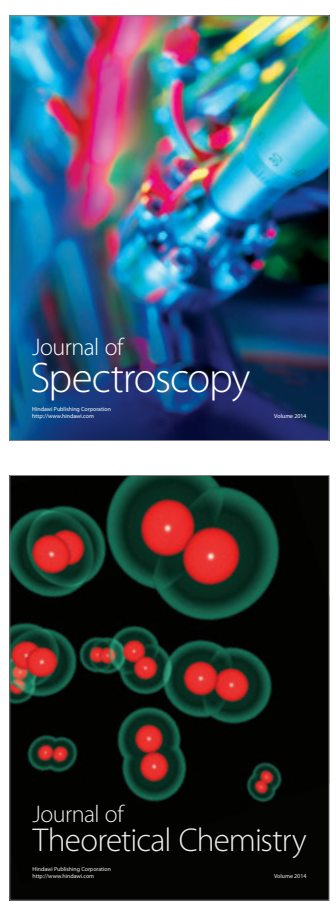
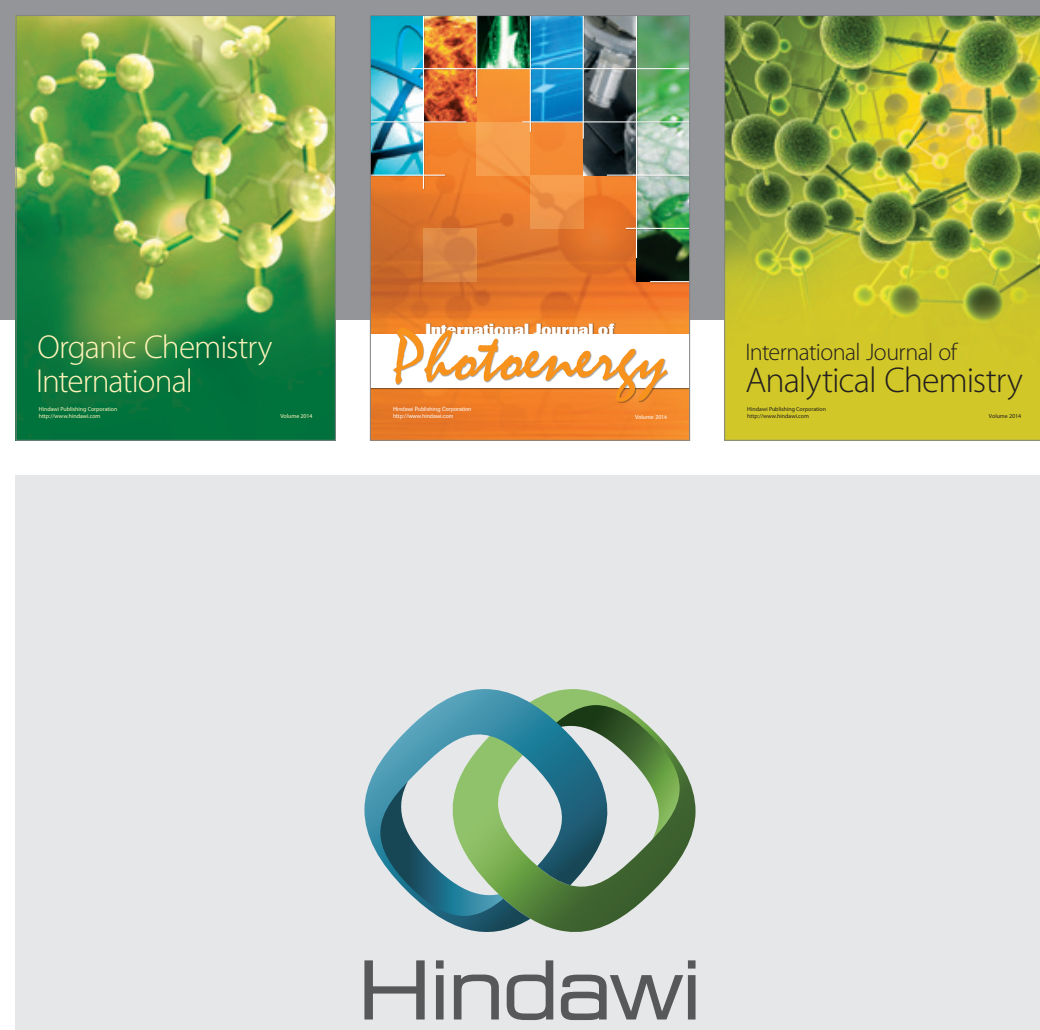

Submit your manuscripts at

http://www.hindawi.com
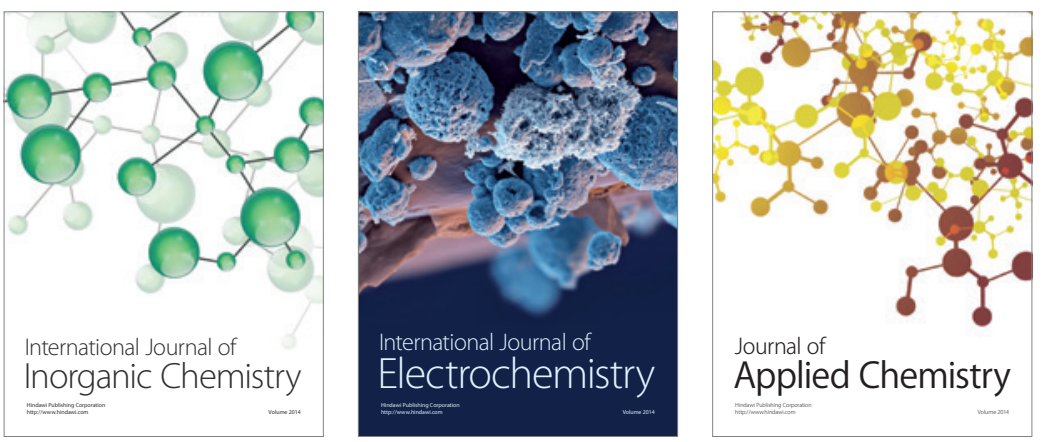

Journal of

Applied Chemistry
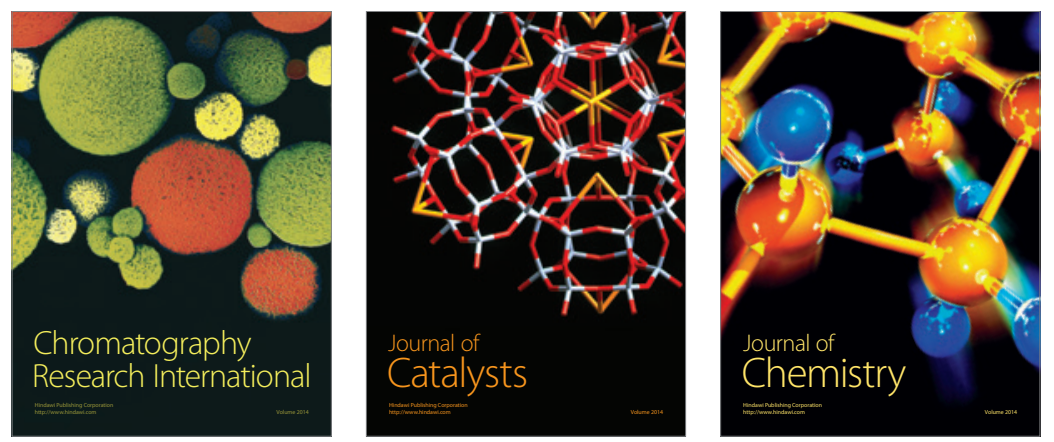
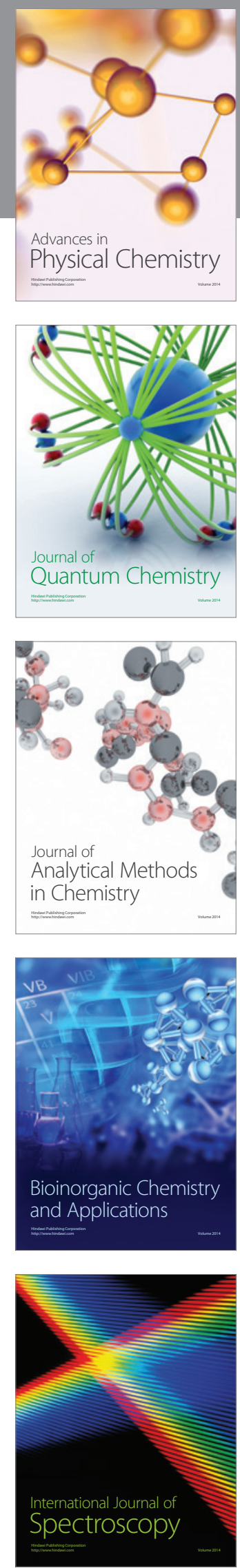